\title{
BMJ Open The road to hell is paved with good intentions: the experience of applying for national data for linkage and suggestions for improvement
}

\author{
Julie A Taylor (D) , ${ }^{1}$ Sonya Crowe (D) , ${ }^{1}$ Ferran Espuny Pujol (D) , ${ }^{1}$ \\ Rodney C Franklin, ${ }^{2}$ Richard G Feltbower, ${ }^{3}$ Lee J Norman, ${ }^{3}$ James Doidge (i) ,,5 \\ Doug William Gould (i) , ${ }^{4}$ Christina Pagel (i) ${ }^{1}$
}

To cite: Taylor JA, Crowe S, Espuny Pujol F, et al. The road to hell is paved with good intentions: the experience of applying for national data for linkage and suggestions for improvement. BMJ Open 2021;11:e047575. doi:10.1136/ bmjopen-2020-047575

- Prepublication history for this paper is available online. To view these files, please visit the journal online (http://dx.doi org/10.1136/bmjopen-2020047575).

Received 02 December 2020 Accepted 27 July 2021
Check for updates

(c) Author(s) (or their employer(s)) 2021. Re-use permitted under CC BY-NC. No commercial re-use. See rights and permissions. Published by BMJ.

For numbered affiliations see end of article.

Correspondence to

Ms Julie A Taylor;

julie.a.taylor@ucl.ac.uk

\section{ABSTRACT}

Background We can improve healthcare services by better understanding current provision. One way to understand this is by linking data sets from clinical and national audits, national registries and other National Health Service (NHS) encounter data. However, getting to the point of having linked national data sets is challenging. Objective We describe our experience of the data application and linkage process for our study 'LAUNCHES $\mathrm{Ql}$ ', and the time, processes and resource requirements involved. To help others planning similar projects, we highlight challenges encountered and advice for applications in the current system as well as suggestions for system improvements.

Findings The study set up for LAUNCHES QI began in March 2018, and the process through to data acquisition took 2.5 years. Several challenges were encountered, including the amount of information required (often duplicate information in different formats across applications), lack of clarity on processes, resource constraints that limit an audit's capacity to fulfil requests and the unexpected amount of time required from the study team. It is incredibly difficult to estimate the resources needed ahead of time, and yet necessary to do so as early on as funding applications. Early decisions can have a significant impact during latter stages and be hard to change, yet it is difficult to get specific information at the beginning of the process.

Conclusions The current system is incredibly complex, arduous and slow, stifling innovation and delaying scientific progress. NHS data can inform and improve health services and we believe there is an ethical responsibility to use it to do so. Streamlining the number of applications required for accessing data for health services research and providing clarity to data controllers could facilitate the maintenance of stringent governance, while accelerating scientific studies and progress, leading to swifter application of findings and improvements in healthcare.

\section{THE OPPORTUNITY}

In the UK, challenges exist for many lifelong conditions such as congenital heart disease (CHD), ${ }^{1}$ cancer, ${ }^{2}$ renal disease, ${ }^{3}$ haemophilia ${ }^{4}$

\section{Strengths and limitations of this study}

- Provide valuable advice and insight to those embarking on research requiring linked national data sets, reassurance to those currently negotiating the system and suggest improvements throughout the data application ecosystem for the future.

- Our experiences will overlap with those of prospective patient recruiting studies and clinical trials.

- This is a single study using linked retrospective audit data, applicability of experiences and advice may vary according to the readers requirements.

- Clinical trials and studies recruiting participants will have a greater document burden than described here, but may also have found that the system was more applicable to their research than for retrospective data analysis.

- The data sets applied for covered English centres only, as national data would have required several additional applications.

and cystic fibrosis. ${ }^{5}$ The UK has a wealth of high-quality registry and audit data.

We can improve healthcare services by better understanding current provision and outcomes $^{6}$ through linking data sets from clinical and national audits, registries and other National Health Service (NHS) activity data. In our research study, LAUNCHES QI (box 1), we are using five linked national data sets to generate important understanding about services for CHD.

\section{THE PROBLEM}

Linking five national data sets has been challenging, laborious and at times demoralising and seemingly hopeless. Coordinating applications to multiple data controllers and navigating the terminology, legal and governance 
Box 1 Description of the LAUNCHES QI study and its data application process

LAUNCHES QI: Linking AUdit and National data sets in Congenital HEart Services for Quality Improvement

The aim of LAUNCHES is to improve services for congenital heart disease and provide a template for other lifelong conditions by linking five national data sets to: describe patient trajectories through secondary and tertiary care; identify useful metrics for driving quality improvement (QI) and informing commissioning and policy; explore variation across services to identify priorities for $\mathrm{Ql}$.

\section{Data application process}

Planning the linkage process began with preparing the funding application. At that stage we liaised with each of the audits and developed an initial plan for linkage, including timelines and costs. This necessarily involved some guess work and we ended up underestimating both the time and costs involved.

The data application process in earnest (see figure 1) began in March 2018, with the start of the funding. The core data set was the National Congenital Heart Disease Audit (NCHDA) data set including cases from April 2000 to March 2017. Patients within NCHDA were matched to records in the Paediatric Intensive Care Audit Network (PICANet), Intensive Care National Audit and Research Centre-Case Mix Programme (ICNARC-CMP), Hospital Episode Statistics (HES) and Office for National Statistics (ONS) mortality data. Resulting in a linked data set allowing the analysis of longitudinal patient trajectories through the healthcare system. The data controller for NCHDA and PICANet is the Health Quality Improvement Partnership, for ICNARC-CMP is ICNARC and for HES and ONS is NHS Digital.

Our initial linkage plan was to use NHS Digital to act as a 'trusted third party', recommended as a standard approach to data linkage. However, following one of the author's experience and discussions with audit partners about risks of delay and feasibility, we opted for a method where each data controller linked their own data to the NCHDA identifiers.

Before beginning the process we met with colleagues attempting a similar study and were able to draw on their experience and use their draft forms, and our study coordinator had prior experience applying to NHS Digital, so we consider that we had a head start that potentially reduced the time taken to receive approvals. We had allowed 6 months to complete this process, and expected to have the linked five data sets ready for analysis shortly after this.

Required first were university approvals for: data protection, insurance, information governance and approval of the completed Integrated Research Application System application, protocol and other study documents. This information and approvals made up the document set (table 1) to submit to the Research Ethics Committee (required as LAUNCHES involved patients identified in the context of their past use of services in the National Health Service), and the Confidentiality Advisory Group to apply for section 251 approval to link and process the data (as it is not feasible to contact patients from the audits for retrospective individual consent). While these applications were under review, we could begin the four data applications for the five data sets, to submit for approval to the three data controllers.

structures can feel overwhelming. The process is timeconsuming, complex and iterative.

Although we are a single study, much of the LAUNCHES process will be applicable to other studies, although with variations in university/institutional requirements, research ethics committee (REC) requirements, the legal basis through General Data Protection Regulation (GDPR) compliance and the common law duty of confidentiality, and data controller specific requirements (figure 1).

\section{OUR INTENTION}

We hope to help others applying for and linking registry, health administration and audit data sets by describing the processes, duration, resource requirements and challenges involved in LAUNCHES and offering some advice and suggestions for system improvements based on our experience. We hope this paper will contribute to a renewed national conversation about balancing justifiably stringent requirements of data protection and governance with the potential opportunity for beneficial research capitalising on the wealth of healthcare data available. ${ }^{7-13}$

\section{CHALLENGES AND LEARNING \\ Volume of information required}

Table 1 details the full set of documents for the data application processes (47 in total comprising 384 pages), which were required by 11 controllers or departments and submitted 162 times in total. Although similar study information was requested for each of the seven application forms and the protocol, each required different wording, structure and detail. Several documents, designed for clinical trials and other prospective studies recruiting participants, were difficult to adapt to our study context.

Requests for alterations and further information prior to approval were received between one and nine times for each data controller. Additional communications followed, for data preparation and transfer (figure 2).

Following approvals, further follow-up on the study document set was required. Examples are requesting publication of privacy notices on partner websites, submitting amendments, annual reports to ethics and the Confidentiality Advisory Group (CAG) and annual renewals for each data sharing agreement.

\section{Person time required}

It was tricky to assess in advance the person time required. Once the extent of the workload became clearer, we increased our $20 \%$ full-time equivalent (FTE) study coordinator to $40 \%$ FTE for the beginning part of the study, but at the cost of less study coordinator support towards the end of the study (fortunately our funder was supportive). In retrospect the time required from the principal investigators to check, edit and input into the documentation was underestimated.

The teams working at the national audits also had limited resources and on occasions important day-to-day work necessarily took priority over processing data requests.

\section{Costs}

Allocating accurate funds for access to data sets is challenging. (1) It is difficult to anticipate the final costs for 

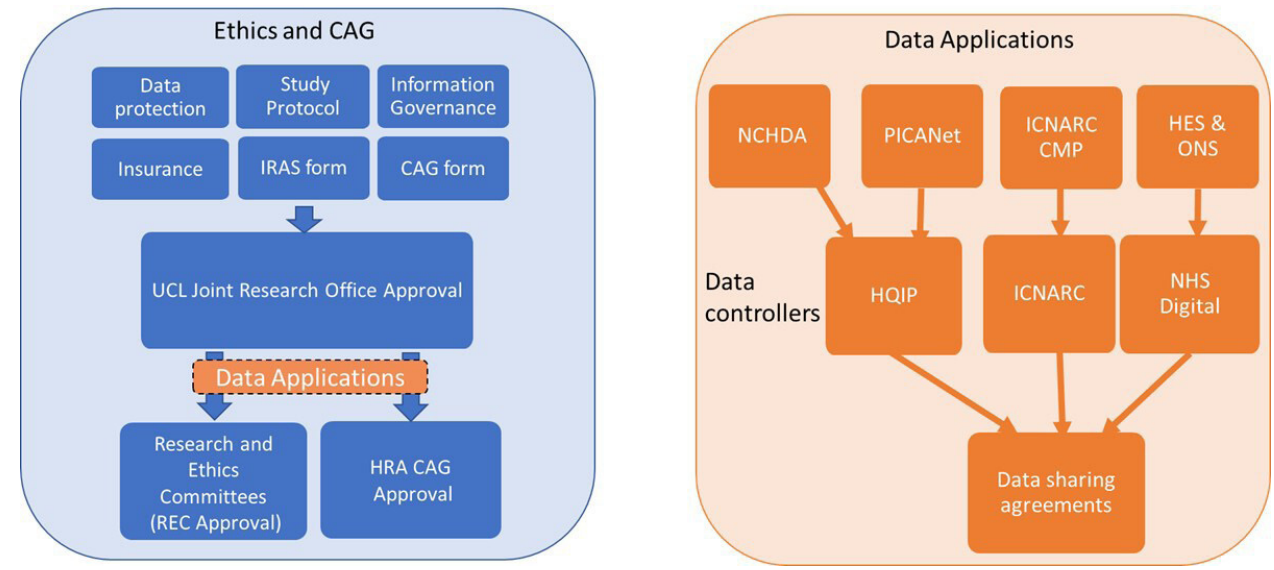

Figure 1 Flow diagram of the study approval and data application process. The right hand orange figure provides the detail in the orange section (data application box) on the left blue hand figure. CAG, Confidentiality Advisory Group; HES, Hospital Episode Statistics; HQIP, Health Quality Improvement Partnership; HRA, Health Research Authority; ICNARC CMP, Intensive Care National Audit and Research Centre Case Mix Programme; IRAS, Integrated Research Application System; NCHDA, National Congenital Heart Disease Audit; NHS, National Health Service; ONS, Office for National Statistics; PICANet, Paediatric Intensive Care Audit Network; REC, research ethics committee; UCL, University College London.

some data sets and they were underestimated in the grant application. (2) Although you apply for data for the full length of the project, you are required to extend the data sharing agreement annually, this required additional funds for charges, study coordination time and principal investigator (PI) time. (3) In the case of NHS Digital, requesting even one additional field after approval could result in a charge equal to that of the original data extract.

\section{Process delays}

A timeline of the process is given in figure 2. Study permissions, including university processes and receiving ethical and CAG approval, took 8 months, and the data applications took between 3 and 7 months. Acquiring the data took a further 7-10 months.

Below we give examples of factors that caused delay and confusion to illustrate how seemingly small decisions had significant consequence and sometimes the complexity was overwhelming.

\section{One small decision...}

Small, seemingly inconsequential, decisions in filling out forms had far reaching consequences which did not become apparent until much later. In our case, a small decision in the Integrated Research Application System (IRAS) filter questions, made early to avoid redoing weeks of initial work on the IRAS form, ultimately ended up creating a lot of extra work. The resulting additional forms and required approvals are still being processed with an NHS site 2 years on.

\section{Lack of clarity}

We applied for two data sets (National Congenital Heart Disease Audit and Paediatric Intensive Care Audit Network) that had the same data controller (Health Quality Improvement Partnership (HQIP)), so we were unsure whether one or two applications were required. We were initially told one (which we prepared) but later told that two were needed. Therefore, two forms were submitted to the same data controller, to be discussed at the same meeting, with virtually identical content but slightly tailored to each specific data set.

\section{Requiring inside knowledge}

Not all fields were listed in data dictionaries, and some derived fields that we asked for (eg, age at an event instead of date) needed negotiation with each data provider. We were lucky to have project partners from each audit who knew that derived fields were possible.

\section{Bureaucracy}

Each time that we recruited research staff, some of the data sharing agreements required updating. Even such a minor change took up to 6 weeks and needed to be done separately for each data agreement, delaying when new staff could begin working with the data.

\section{Being too specific}

For IRAS and CAG we stated that we would be requesting life status and age at last known life status from Office for National Statistics (ONS), but our advisory group subsequently suggested also requesting type of residence at death and hospital name. This change created a cascade of amendments resulting in significant delay. Had we stated that we would be applying for ONS data but not specified the fields, the amendment process would not have been necessary.

\section{Not being specific enough}

It was difficult to know how specific to be. As the data application developed, some changes to the fields were required and making these changes was a lengthy process. In our case, a failure to specify the number of decimal places required for age and our intention to request month and year of birth in our CAG application, coupled with a misunderstanding following asking 


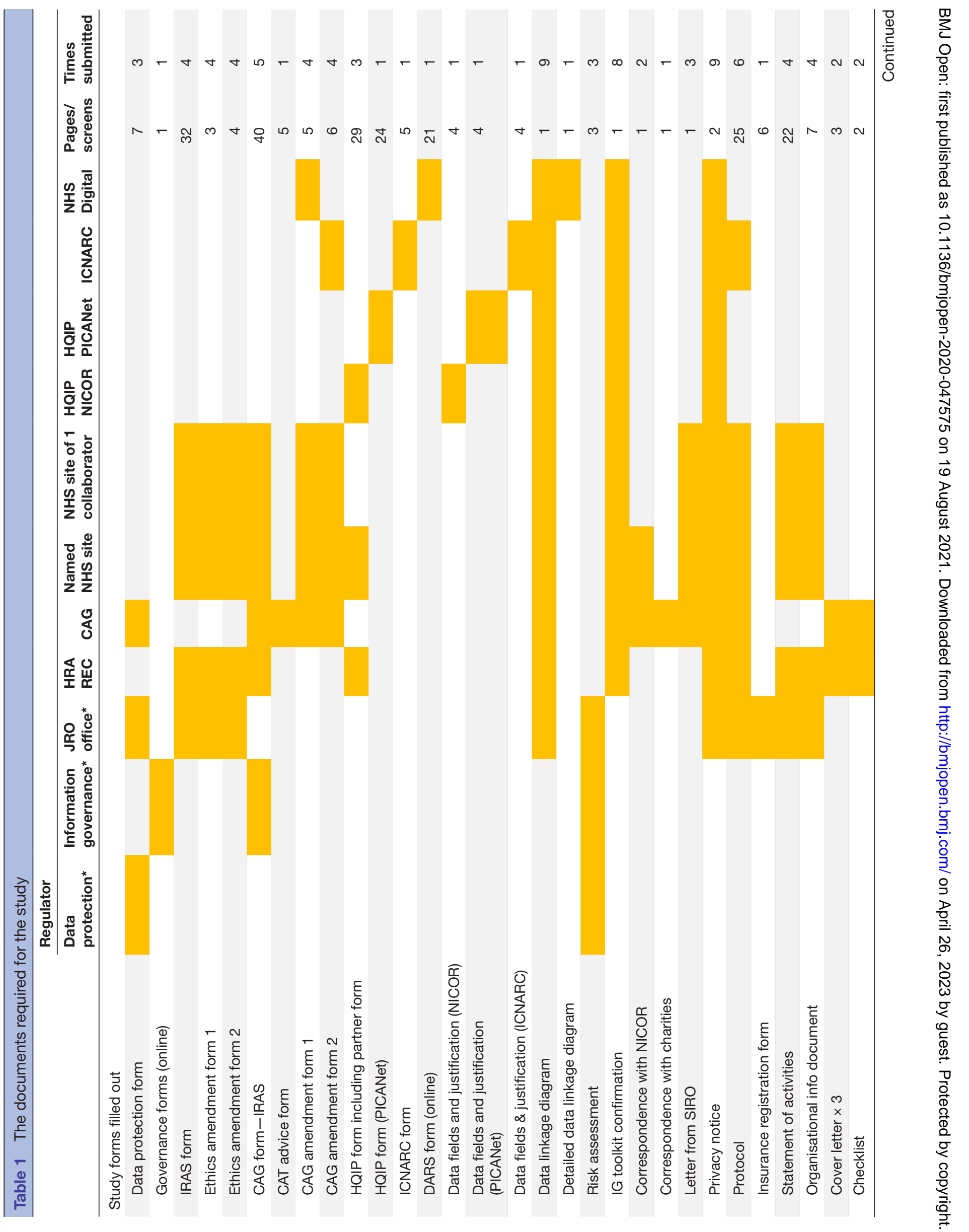




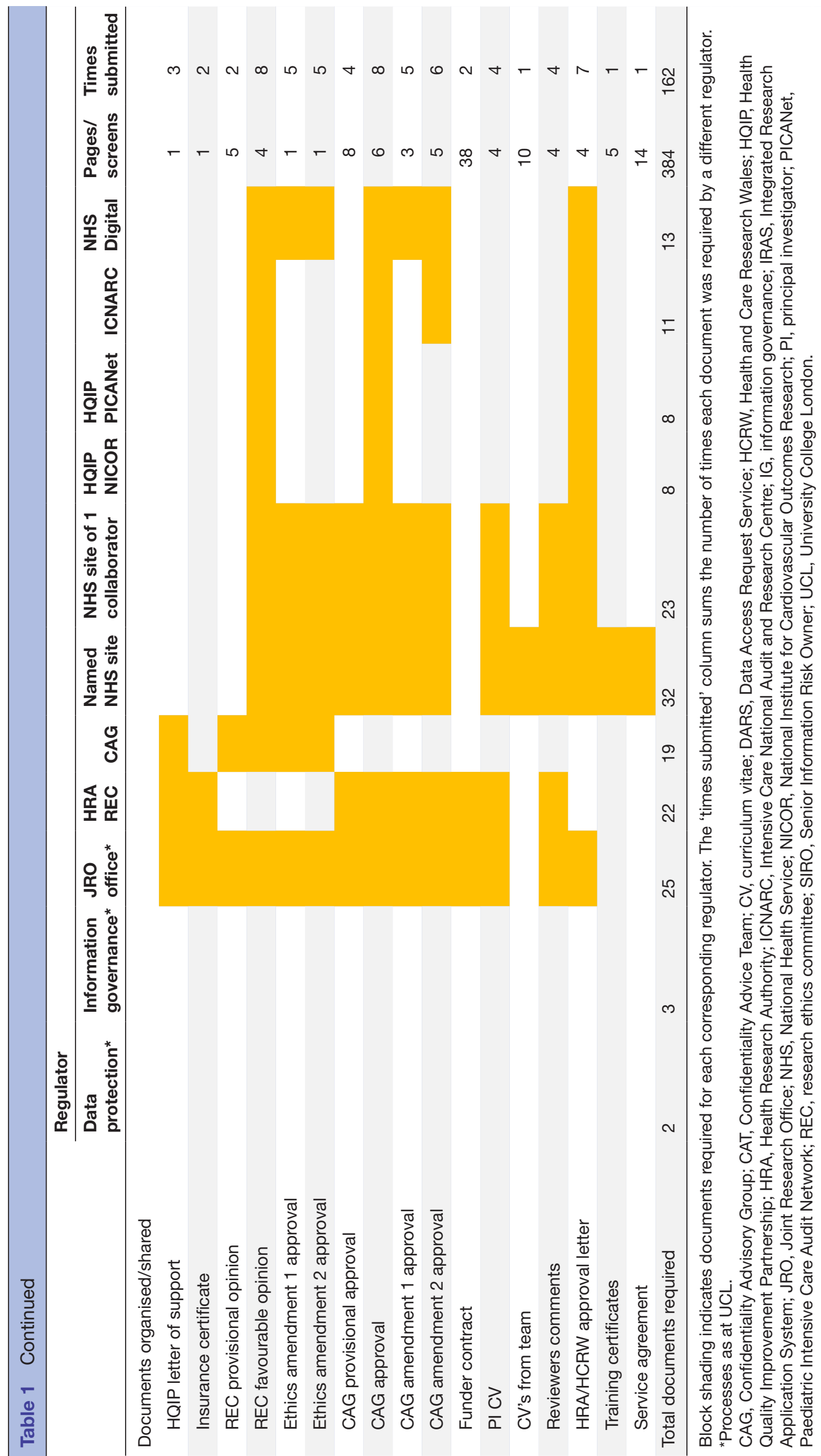




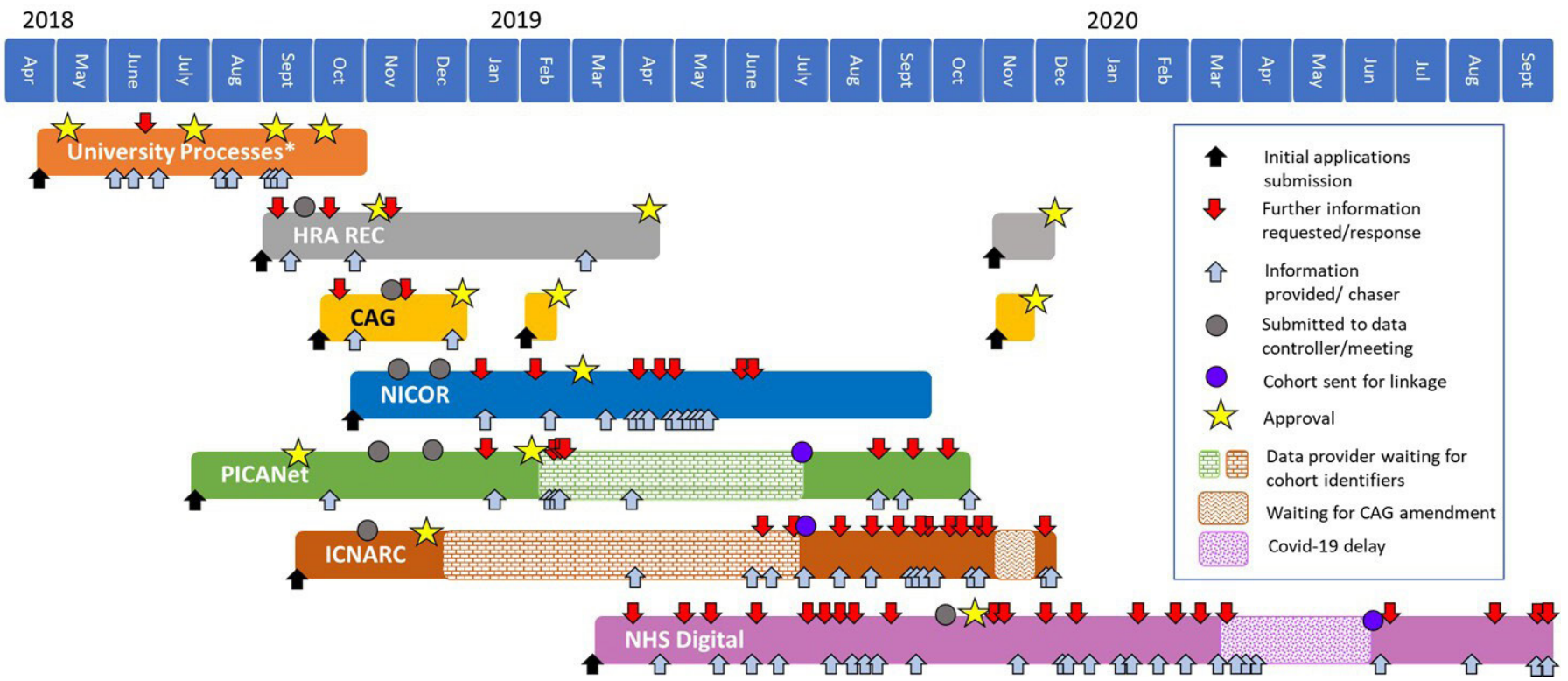

Figure 2 Timeline of the permission process, order and time taken in LAUNCHES QI, from first submission to data acquisition. Each box represents the time from submission of the data application to transfer of the data to UCL, for each data set. Note that not all requests for further information and responses have been included! *Processes as at UCL. CAG, Confidentiality Advisory Group; HRA, Health Research Authority; ICNARC, Intensive Care National Audit and Research Centre; NHS, National Health Service; NICOR, National Institute for Cardiovascular Outcomes Research; PICANet, Paediatric Intensive Care Audit Network; REC, Research Ethics Committee; UCL, University College London.

for date of event in one data set caused problems when it came to data extraction. This required a CAG amendment to resolve.

\section{The impact of infrequent data controller meetings}

In addition to the time spent preparing applications, timing applications to coincide with monthly (or sometimes less frequent) data controller approval meetings was difficult, and not all controllers provide information on meeting dates. Narrowly missing a meeting meant waiting a month or more for the next meeting, and if there were requests for further information then the process was delayed by another month. Additionally, an amendment for one data controller required changes to all other data applications, which lengthened the process considerably. We had five different approval bodies across the data sets.

\section{Maintaining enthusiasm among project partners}

One impact from process delays was the challenge of keeping project partners engaged and enthusiastic. The timeline our partners had originally agreed to had to be extended twice, with few interim developments to report back.

\section{The fear of legal misstep, delaying data sharing}

Failure to comply with the data protection principles could mean a fine of up to $€ 20$ million, or $4 \%$ of an organisation's total worldwide annual turnover, whichever is higher. ${ }^{14}$ Data controllers with good processes in place but without complete clarity on remit potentially contribute to delays because of concerns about a possible breach. For example, one data controller repeatedly asked us to clarify that our collaborators were advisory only, without access to the linked data set, despite us providing that assurance at each stage.

\section{Acquiring data}

Once all approvals are in place, the process to gain access to and link the data are also lengthy. For example, following approval from the data controller (HQIP), it took 7 months for the cohort to then be constructed and matching data sent to the other data providers for linkage.

Acquisition following approvals was delayed by a combination of: limited staff resources in National Institute for Cardiovascular Outcomes Research for initiating linkage with other audits, amendments to obtain specific data fields, CAG amendments and an amendment for a bespoke linkage plan (that was later shelved because of lack of data controller capacity). While some of these delays could have been avoided in hindsight, it is almost impossible to anticipate everything ahead of time, and the process for any changes is often as lengthy as a fresh application.

\section{Reusing the data}

Having completed the data linkage, funding was received for another study that would use the same data set. For most of the data sets, entirely new applications were required to use the existing data for this new but similar purpose, and despite our previous experience in LAUNCHES, it has taken another 2 years to complete the process, with the NHS Digital application still pending. 


\section{USEFUL ADVICE}

\section{Love thy research assistants/study coordinators (the legal} amount)

These are roles that often get squeezed at application stage to reduce costs and can be challenging to resource if part-time. But these roles are absolutely crucial in accessing data.

\section{Find people who have been there before you}

Researchers who were further ahead in their data application journey shared their learning and expertise with us. This helped speed up the initial process of preparing the applications.

\section{Have a flexible start up period}

Having an initial data application period in the project with just the PIs and a study coordinator funded allowed us to react early to delays and quickly adjust the timeline.

\section{Add clinical and audit experts to the team}

Input from clinicians on data fields helped with data minimisation versus research realisation (particularly a problem for exploratory work). We also found it useful to include, where possible, collaborators working for data controllers and audits.

Plan your data minimisation and beware of differences in how some terms are interpreted

You will need to describe how you have minimised the need for patient identifiers, and all fields requested will require justification. In doing so be sure to correctly state if data will be de-identified, pseudonymised or further anonymised. Some consider anonymised data to be aggregate data only, and amendments may be needed to clarify terms.

\section{SYSTEM IMPROVEMENT}

It has taken us over 2.5 years to create our linked data set, so most of our analyses and outputs on what was originally a 2-year project are yet to be completed. But things could have been worse: we have an understanding funder and an incredible study coordinator, and we experienced no project staff turnover or major changes in audit staff.

There is no centralised or easily accessible support for how to navigate the system-each new project team is on its own. So how might the system improve? Below are our suggestions, which are also summarised in figure 3 .

\section{A shorter, streamlined system for retrospective data Ethics and CAG}

The forms for ethical and CAG approval are set up for clinical trials and cohorts prospectively recruiting participants. A shorter application form specific to routinely collected retrospective data would be helpful. CAG have now introduced what is known as the precedent set pathway ${ }^{15}$ to enable a more timely review process, which although a step in the right direction applies only to specific situations, known as the "precedent set

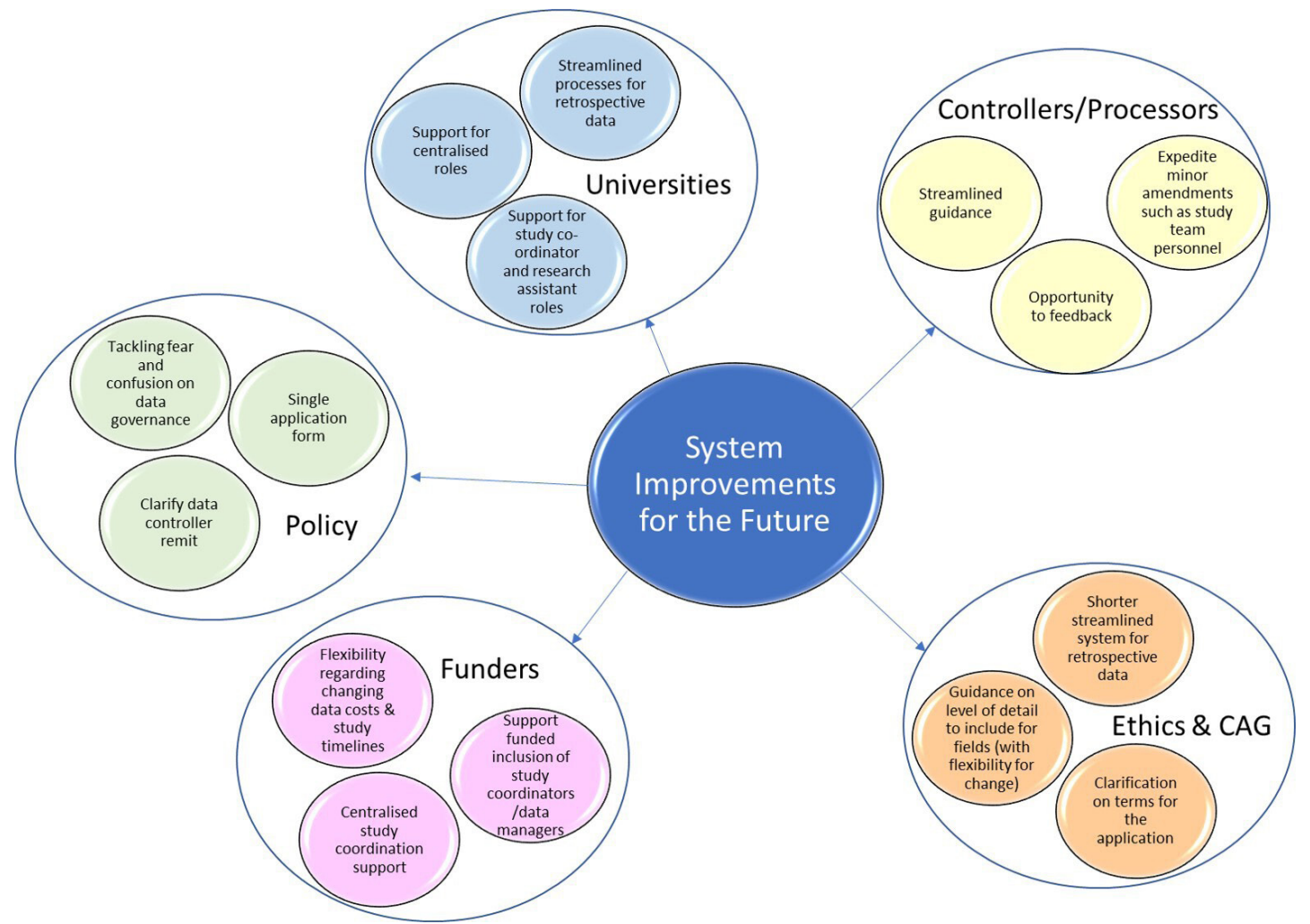

Figure 3 Illustrates the suggested system improvements for the future. The coloured bubbles contain the suggestions, with each larger bubble representing the authority that should consider these changes. CAG, Confidentiality Advisory Group. 
categories'. These categories include: applications to identify a cohort of patients and subsequently seek their consent; accessing data on site to extract anonymised data; validity of consent; data cleansing of historical studies; time limited access to undertake record linkage/ validation and anonymisation of data.

The latter category was not a feasible category for us to apply for expedited review as we required pseudonymised data from each data controller to link all data sets at University College London. The original data linkage plan had involved each audit sending their data to NHS Digital, so we would receive the final linked data set only. However, following feedback from a study that had adopted this strategy, that this had lengthened the process, without them having access to any of the data sets during this time, we opted for each audit completing their own linkage to the core NCHDA dataset. This allowed us to receive and begin working on each data set as it reached us, without needing to have received every data set. NHS Digital was the lengthiest application process and therefore the original planned linkage would have delayed us even further. We did not seek to receive the identifiers from each audit for the sake of data minimisation and governance.

\section{Single application}

A template form with the same questions for all healthcare-related data controllers would reduce workload significantly. Each data controller would receive the same form, with the specification of all fields requested from each data set.

\section{Defined remit}

The various application forms ask several questions regarding patient benefit (eg, anticipated magnitude of patient benefit, how it will be achieved and measured, what contribution universities make to improving patient services, number of planned manuscripts), that are reiterated from funding, REC and CAG, but not consistently required in all data applications.

These questions were sometimes additional to the actual data application forms and so introduced delays as emails were sent back and forth (see figure 2). A joint system between funders, REC/CAG and data controllers so that each could be sure that important questions on feasibility, importance and process have been answered while minimising burden on applicants (and committees within each organisation) would be beneficial. In the absence of such a system, clarity on remit would reduce the pressure on the data controllers with the more conservative approaches to obtain such detailed information, and in some cases prevent duplication of review of ethics, CAG applications, amendments and annual reports. For context, some applications required details of research outputs and benefits. The amendment to use the same data for another study (see 'reusing data') resulted in the re-review of the initial application with further questions on this already approved section. The questions referred to whether some benefits listed would actually be considered outputs. Defining remit could consider the level of detail necessary for each part of the process.

\section{Funders}

Funders are increasingly acknowledging the time it will take to access and link data, and the uncertainties around timing. Additionally, they need to ensure that projects requiring external data have been resourced appropriately with sufficient budget for data access and project management. A more ambitious response could be centralised project coordinators within funding bodies that are assigned to successful projects to help manage data access. This may be more efficient as the funders would build up expertise and experience of data access processes and make it easier to resource part-time project coordination.

\section{Data controllers/processors; REC and CAG}

Staff at the point of contact (on both sides) are bearing the brunt of the frustrated emails and the fraying patience of applicants working to their deadlines. Audits are working hard, encompassing much more than providing data to researchers, with their own staffing and resource issues and have to abide by stringent data governance rules. The underlying systems seem to be the problem, but there are few opportunities for feedback.

Available guidance needs streamlining as it is currently lengthy, spread across a number of web pages and often hard to follow or ambiguous. Some independent organisations have attempted to provide guidance to help navigate the system. For example, the Medical Research Council have developed an online tool to help determine the approvals needed, ${ }^{16}$ and HQIP have just funded and published short films and written resources on understanding health data access designed to improve accessible, introductory information about the rules and processes governing access to health data. ${ }^{17}$

Another possibility being adopted in other countries ${ }^{1819}$ is a central authority for processing and approving applications, and implementing linkage, thereby reducing the number of data controllers carrying out effectively the same review, and increasing efficiency. However, some countries adopting such systems have reported that such systems are not without delays and problems and that further improvements are required. ${ }^{19-21}$

\section{Universities}

Research assistants/study coordinators are really important for the success of this kind of research and play vital roles in information governance and data security, yet they are often funded on rolling temporary contracts with no job security or progression, often resulting in the loss of valuable expertise and experience. Universities should consider how to protect these roles, for example, they could support permanent, centralised study coordinators who could assist several projects across the 
university. Similar problems of job security also affect the data processors.

We also experienced an increase in the requirements of the research and development ('R\&D') departments of the universities and the NHS sites, with little if any flexibility to take study type into account.

\section{Tackling fear and confusion over data protection}

How GDPR and other data protection laws apply to these sorts of retrospective studies is hard to understand and open to different interpretations. The importance of data governance and potential penalties for breaching GDPR mean that often the most conservative interpretation is used which often increases the complexity and workload. Clearer guidance, a single form and clarification on remit would alleviate this, as would guidance on the inclusion of collaborators and processes to share data after a data set is established.

\section{LESSONS FROM THE PANDEMIC}

During 2020, research governance was relaxed in pursuit of rapid scientific evidence into COVID-19 aetiology, risk factors and treatments. This included a fast track review for ethics review, ${ }^{22}$ the pause of the need for approval under Regulation 3 (4) of the Health Service Control of Patient Information Regulations $2002^{23}$ and the release of data and change in process by some data controllers. ${ }^{24}$ This expedited progress of all studies into COVID-19, and prioritisation of COVID-19 research, shows that there is room to simplify the process. ${ }^{10}$ This provides an important opportunity to learn from what happened during the COVID-19 pandemic, and what could be adapted for the future.

\section{Strengths and limitations}

Our experience of an ambitious project to link five data sets may not be entirely generalisable to other researchers, especially those applying for fully anonymised data from an established research database.

However for most studies, although some differences would apply for ethics and CAG requirements, such requirements will still need to be considered at the outset of the study. Data sets required will differ for different projects, but we expect that each research team will encounter similar governance requirements although with different requirements of the relevant data controllers. Longitudinal studies and clinical trials may have many approvals in place, but may be still experiencing their own challenges with changing governance requirements that could delay renewal of permissions.

Our challenges were not unique, ${ }^{711} 1325$ and align with other recommendations that have been suggested. ${ }^{810132627}$ The publication of our experience is an important addition to the research method dissemination, hopefully facilitating the development of new and more efficient data access systems.

\section{Conclusions}

The current system is incredibly complex, arduous and slow, stifling innovation and delaying scientific progress. NHS data can inform and improve health services and we believe there is an ethical responsibility to use it to do so. ${ }^{12}$

Streamlining the number of applications required for accessing data for health services research and providing clarity to data controllers will facilitate the maintenance of stringent governance, while accelerating scientific studies and progress, leading to swifter application of findings and improvements in healthcare.

\section{Author affiliations}

${ }^{1}$ Clinical Operational Research Unit, Department of Mathematics, University College London, London, UK

${ }^{2}$ Paediatric Cardiology Department, Royal Brompton and Harefield NHS Foundation Trust, London, UK

${ }^{3}$ Paediatric Intensive Care Audit Network, University of Leeds, Leeds, UK

${ }^{4}$ Intensive Care National Audit and Research Centre, London, UK

${ }^{5}$ Department of Medical Statistics, London School of Hygiene and Tropical Medicine, London, UK

Twitter Christina Pagel @chrischirp

Acknowledgements We would like to thank the data application teams at PICANet, ICNARC, NICOR, HQIP and NHS Digital for their help and guidance as we negotiated the data application system.

Contributors CP, SC and JAT were involved in conceptualisation, design and writing of the manuscript, JAT wrote the first draft. CP, SC, JAT, FEP, RCF, RGF, LJN, JD and DWG were involved in the review of the manuscript.

Funding This study is supported by the Health Foundation, an independent charity committed to bringing about better health and healthcare for people in the UK (Award number 685009).

Competing interests None declared.

Patient consent for publication Not required.

Provenance and peer review Not commissioned; externally peer reviewed.

Open access This is an open access article distributed in accordance with the Creative Commons Attribution Non Commercial (CC BY-NC 4.0) license, which permits others to distribute, remix, adapt, build upon this work non-commercially, and license their derivative works on different terms, provided the original work is properly cited, appropriate credit is given, any changes made indicated, and the use is non-commercial. See: http://creativecommons.org/licenses/by-nc/4.0/.

\section{ORCID iDs}

Julie A Taylor http://orcid.org/0000-0002-7698-6991

Sonya Crowe http://orcid.org/0000-0003-1882-5476

Ferran Espuny Pujol http://orcid.org/0000-0001-9085-7400

James Doidge http://orcid.org/0000-0002-3674-3100

Doug William Gould http://orcid.org/0000-0003-4148-3312

Christina Pagel http://orcid.org/0000-0002-2857-1628

\section{REFERENCES}

1 Brown KL, Crowe S, Franklin R, et al. Trends in 30-day mortality rate and case mix for paediatric cardiac surgery in the UK between 2000 and 2010. Open Heart 2015;2:e000157.

2 Kowalczyk JR, Samardakiewicz M, Pritchard-Jones K, et al. European survey on standards of care in paediatric oncology centres. Eur J Cancer 2016;61:11-19.

3 Plumb LA, Hamilton AJ, Inward CD, et al. Continually improving standards of care: the UK renal registry as a translational public health tool. Pediatr Nephrol 2018;33:373-80. 
4 Dolan G, Makris M, Bolton-Maggs PHB, et al. Enhancing haemophilia care through registries. Haemophilia 2014;20 Suppl 4:121-9.

5 Stern M, Bertrand DP, Bignamini E, et al. European cystic fibrosis society standards of care: quality management in cystic fibrosis. J Cyst Fibros 2014;13:S43-59.

6 Deeny SR, Steventon A. Making sense of the shadows: priorities for creating a learning healthcare system based on routinely collected data. BMJ Qual Saf 2015;24:505-15.

7 Mourby MJ, Doidge J, Jones KH, et al. Health data linkage for UK public interest research: key obstacles and solutions. Int J Popul Data Sci 2019;4:1093.

8 Jones KH, Heys S, Tingay KS, et al. The good, the bad, the Clunky: improving the use of administrative data for research. Int J Popul Data Sci 2018;4:587.

9 Jones KH, Ford DV. Population data science: advancing the safe use of population data for public benefit. Epidemiol Health 2018;40:e2018061.

10 Cavallaro FL-W, Cannings-John F;, R; Harron K. Reducing barriers to data access for research in the public interest-lessons from covid-19. BMJ Opinion 2020

11 Dattani N, Hardelid P, Davey J, et al. Accessing electronic administrative health data for research takes time. Arch Dis Child 2013;98:391-2

12 Jones KH, Laurie G, Stevens L, et al. The other side of the coin: harm due to the non-use of health-related data. Int J Med Inform 2017;97:43-51

13 Lugg-Widger FV, Angel L, Cannings-John R, et al. Challenges in accessing routinely collected data from multiple providers in the UK for primary studies: managing the morass. Int J Popul Data Sci 2018;3:432.

14 Data protection act: part 6 enforcement; penalties. section 155-159, 2018. Available: https://www.legislation.gov.uk/ukpga/2018/12/part/ $6 /$ crossheading/penalties/enacted

15 The CAG precedent set review pathway 2020 [updated 20/10/2020], 2020. Available: https://www.hra.nhs.uk/about-us/committees-andservices/confidentiality-advisory-group/cag-precedent-set-reviewpathway/ [Accessed 21 Oct 2020].
16 UKRI MRC Regulatory Support Centre. Health data access tool kit. Available: https://hda-toolkit.org/story_html5.html [Accessed 1 Jun 2021].

17 Health Quality Improvement Partnership. Understanding health data access (UHDA). [Online guidance]. Available: https://www.hqip.org. uk/understanding-health-data-access/\#.YKuVhKhKg2w [Accessed 1 Jun 2021].

18 Oderkirk J, Ronchi E, Klazinga N. International comparisons of health system performance among OECD countries: opportunities and data privacy protection challenges. Health Policy 2013;112:9-18.

19 O'Reilly D, Bateson O, McGreevy G, et al. Administrative Data Research Northern Ireland (ADR Ni). Int J Popul Data Sci 2020;4:1148.

20 Nelson E, Burns F. Impact through engagement: co-production of administrative data research and the approach of the administrative data research centre Northern Ireland. Int J Popul Data Sci 2020;5:1369.

21 Van Der Wel KA, Östergren O, Lundberg O, et al. A gold mine, but still no Klondike: Nordic register data in health inequalities research. Scand J Public Health 2019;47:618-30.

22 NHS Health Research Authority. Fast track review guidance for COVID-19 studies. [updated 20/05/2021]. Available: https://www. hra.nhs.uk/covid-19-research/fast-track-review-guidance-covid-19studies/ [Accessed 1 Jun 2021]

23 Department of Health and Social Care. Coronavirus (COVID-19): notification to organisations to share information, 2020. Available: https://www.gov.uk/government/publications/coronavirus-covid-19notification-of-data-controllers-to-share-information

24 NHS Digital. DARS coronavirus (COVID-19) response [updated 26/05/2021]. Available: https://digital.nhs.uk/services/data-accessrequest-service-dars [Accessed 01 Jun 2021].

25 Macnair A, Love SB, Murray ML, et al. Accessing routinely collected health data to improve clinical trials: recent experience of access. Trials 2021;22:340.

26 Gilbert R, Lafferty R, Hagger-Johnson G, et al. GUILD: guidance for information about linking data sets. J Public Health 2018;40:191-8.

27 Rivera DR, Gokhale MN, Reynolds MW, et al. Linking electronic health data in pharmacoepidemiology: appropriateness and feasibility. Pharmacoepidemiol Drug Saf 2020;29:18-29. 